\title{
Study of atrazine adsorption kinetics by using an activated carbon synthesised from water hyacinth
}

\author{
Pawinee Deetae ${ }^{1}$, and Patthranit Wongpromrat ${ }^{2, *}$ \\ ${ }^{1}$ Division of Industrial Fermentation Technology, Faculty of Agro-Industry, King Mongkut's \\ Institute of Technology Ladkrabang, Bangkok, Thailand \\ ${ }^{2}$ Department of Chemical Engineering, Faculty of Engineering, King Mongkut's Institute of \\ Technology Ladkrabang, Bangkok, Thailand
}

\begin{abstract}
In this work, atrazine, one of the most widely used herbicides in Thailand, was removed from water by activated carbon synthesized from water hyacinth. Before adsorption, 3 types of activated carbons used as adsorbents were prepared by different chemical treatment methods; untreated activated carbon (AC), HCl-treated activated carbon (HCl-AC) and $\mathrm{NaOH}$-treated activated carbon (NaOH-AC). After pyrolysis, $\mathrm{NaOH}-\mathrm{AC}$ became ash, so it was not suitable for using as an adsorbent. Brunauer-Emmett-Teller (BET) and CHNS methods were used to characterised 2 other adsorbents and the results showed that $\mathrm{HCl}$ treatment could improve the surface area and carbon content. This led to the better performance of $\mathrm{HCl}-\mathrm{AC}$ for removing atrazine from water comparing to $\mathrm{AC}$ confirming by the adsorption experiments. In addition, the adsorption kinetics of $\mathrm{HCl}-\mathrm{AC}$, the best adsorbent in this research, was investigated by fitting with 4 kinetics models. The results showed that pseudo-secondorder was the best kinetics model describing that the atrazine adsorption of $\mathrm{HCl}-\mathrm{AC}$ was limited by adsorption and 2 active sites of adsorbent were required for adsorbing 1 molecule of atrazine.
\end{abstract}

\section{Introduction}

Since Thailand is an agricultural country where exports various kinds of agricultural products, so there is the usage of the pesticides for producing and controlling high-quantity and quality of agricultural products. The Office of Agricultural Economics of Thailand reports that, during 2010-2015, Thailand imports the large amount with high value of pesticides [1] and one of the most imported pesticide is atrazine, $\left(\mathrm{C}_{8} \mathrm{H}_{14} \mathrm{ClN}_{5}\right)$ which is the organochloride chemical [2]. Atrazine is used to control weeds in farms and crop land sand for example corn, sugarcane, or millet farm. Due to their extensive usage and its long halflife about 13-261 days in soil and more than 200 days in water resources [3], the contaminations of atrazine in surface water and ground water are the big problem in Thailand [4]. Furthermore, it also affects to frog mutation [5], ecology [4] and human

\footnotetext{
*Corresponding author: patthranit.wo@kmitl.ac.th
} 
health [6]. Thus, because of its hazard, the removal of atrazine from water resources is needed for protecting the human, animals and environments.

There are several techniques for removing atrazine from water, e.g. incineration, reverse osmosis, electrodialysis, chemical degradation and etc. However, all of these techniques are costly and produce corrosive and toxic gases [7]. One of the most attractive method is adsorption because of its simplicity. The common adsorbent used for removing the chemicals contaminating in water is an activated carbon because of its high surface area and porosity. Nevertheless, the activated carbon is an expensive material, thus a low cost effective activated carbon that can be used to remove the contaminant from water should be developed. One property affecting the adsorption capacity is porosity which depends on nature of raw material and activation method. Meanwhile, Thailand has the large amount of agricultural wastes, e.g. coconut shell, watermelon peel, rice straw and etc., consisting of carbon as a major component. These wastes have been studied for using as the activated carbon and the literatures found that they are the effective adsorbents [8-14]. In this study, water hyacinth (Eichhornia crassipes), a free-floating perennial aquatic plant which can propagate and grow easily, was selected to developed for removing atrazine from water due to its large amount causing a rotten water because oxygen cannot dissolve into water, a block of waterways, the effects to both navigation and drainage, and the increasing of siltation and flooding probability [15].

In the consequence, this study aims to prepare a low cost activated carbon from water hyacinth for atrazine adsorption. This means that this study changes the waste (water hyacinth) into a valuable material. As a complex structure of atrazine, chemical and physical treatments are required in order to increase the porosity of water hyacinth. The effect of different kinds of activated carbon preparation methods on adsorption was investigated. In addition, the adsorption kinetics of the best adsorbent prepared in this work was determined.

\section{Experiments}

\subsection{Adsorbent preparation method}

Firstly, the stem of water hyacinth was peeled, cleaned and chopped into pieces with the thickness of about $0.2 \mathrm{~cm}$ and dried under the sunlight for 3 days. Then, the stem pieces were baked for removing water at $105^{\circ} \mathrm{C}$ until constant weight was obtained. After that, it was cooled down to room temperature and treated by 3 different methods as follow:

- Untreated Method: No chemically treated was required for this method. The activated carbon obtained is abbreviated as $\mathrm{AC}$ in the following.

- HCl-treated Method: The 10-g of dried water hyacinth was left in $1 \mathrm{~L}$ of HCl solution with the concentration of $1 \mathrm{M}$ for 2 days. After that, it was separated by filtration, washed by distilled water until the $\mathrm{pH}$ of washed water was neutral and baked at $105^{\circ} \mathrm{C}$ for 2 days. The activated carbon attained from this method is called HCl-AC in the following.

- NaOH-treated Method: The preparation of the activated carbon prepared from this method, $\mathrm{NaOH}-\mathrm{AC}$, was similar to that of $\mathrm{HCl}-\mathrm{AC}$, but $\mathrm{NaOH}$ was used as a treating chemical instead of $\mathrm{HCl}$.

After chemical treatment, the materials were pyrolysed at $500^{\circ} \mathrm{C}$ under $\mathrm{N}_{2}$ in the furnace for $1 \mathrm{~h}$. After cooling to room temperature, the activated carbons prepared from 3 different methods were obtained. They were ground and sieved to be $200-250$ mesh-size. After that, the characterisations of adsorbents were achieved and the adsorption experiments were performed. 


\subsection{Material characterisations}

The adsorbents prepared from the methods mentioned above were characterised by Brunauer-Emmett-Teller (BET) in order to observe the surface areas, pore volumes and pore diameters and CHNS Analysis for identifying the compositions of the adsorbents.

\subsection{Adsorption experiments}

The adsorption experiments in this work were performed by batch test with the volume of atrazine solution of $200 \mathrm{~mL}$. The amount of adsorbent used in each batch was $0.1 \mathrm{~g}$ and the agitation speed was controlled at $150 \mathrm{rpm}$. The samples were taken at the appropriate time intervals and the atrazine concentrationa in the samples were analysed by Gas Chromatography-Mass Spectroscopy (GC-MS) with HP-5 method.

\section{Results and discussion}

\subsection{Material characterisations}

After pyrolysis of water hyacinth treated by $\mathrm{NaOH}$, this material partly became ash. This was probably due to the better lignin removal ability of $\mathrm{NaOH}$ than $\mathrm{HCl}$ [16], so the amount of $\mathrm{NaOH}$-treated water hyacinth pyrolysed was less than that of other treating methods. According to high temperature of pyrolysis process, $\mathrm{NaOH}$-treated water hyacinth was partly transformed into ash. Hence, $\mathrm{NaOH}-\mathrm{AC}$ was not studied in the part of adsorption performance in this work.

Table 1 reports the carbon percentages $(\% \mathrm{C})$, surface areas and pore diameters of $\mathrm{AC}$ and $\mathrm{HCl}-\mathrm{AC}$ characterized by CHNS Analysis and BET. It can be seen that the surface area and $\% \mathrm{C}$ of $\mathrm{HCl}-\mathrm{AC}$ were higher than those of $\mathrm{AC}$. This revealed that chemical treatment by $\mathrm{HCl}$ could improve both $\% \mathrm{C}$ and surface area of the adsorbent since $\mathrm{HCl}$ removed lignin in the water hyacinth. Taking into account the pore diameters of $\mathrm{AC}$ and $\mathrm{HCl}-\mathrm{AC}$, the pore diameter of $\mathrm{HCl}-\mathrm{AC}$ was finer than that of $\mathrm{AC}$ about 2.8 times. Fortunately, the atrazine diameter is about $10.36 \AA$ [17] which is still smaller than the pore diameter of $\mathrm{HCl}-\mathrm{AC}$. Therefore, among these, $\mathrm{HCl}-\mathrm{AC}$ should be the best adsorbent for removing atrazine from water since it had the highest $\% \mathrm{C}$ and surface area while its pore diameter was still bigger than the size of atrazine.

Table 1. Characteristics of the adsorbents.

\begin{tabular}{|c|c|c|c|}
\hline Adsorbent & \%C & Surface area $\left(\mathbf{m}^{2} / \mathbf{g}\right)$ & Pore diameter $(\mathbf{\AA})$ \\
\hline AC & 38.921 & 160.4 & 80.94 \\
\hline HCl-AC & 71.192 & 436.0 & 29.01 \\
\hline
\end{tabular}

\subsection{Adsorption kinetics study}

The hypothesis obtained from the previous that $\mathrm{HCl}-\mathrm{AC}$ was probably the best adsorbent in this work was proven by adsorption experiments. $\mathrm{AC}$ and $\mathrm{HCl}-\mathrm{AC}$ were used to adsorb 
atrazine with the initial concentration of about $12 \mathrm{ppm}$. The results, Fig.1, show that the times to equilibrium of $\mathrm{AC}$ and $\mathrm{HCl}-\mathrm{AC}$ were about 4 and $5 \mathrm{~h}$, respectively, and the remaining atrazine concentrations in solution when $\mathrm{AC}$ and $\mathrm{HCl}-\mathrm{AC}$ were used as the adsorbents were about 5 and $3 \mathrm{ppm}$ and the atrazine removal efficiencies of $\mathrm{AC}$ and $\mathrm{HCl}-\mathrm{AC}$ were $60.95 \%$ and $75.90 \%$, respectively. That means the capacity of $\mathrm{HCl}$-AC was higher than that of $\mathrm{AC}$, so this experiments confirmed the results of BET and CHNS Analysis that the performance for atrazine adsorption of $\mathrm{HCl}-\mathrm{AC}$ was better than that of $\mathrm{AC}$ and $\mathrm{HCl}-\mathrm{AC}$ was the best adsorbent in this work. Thus, for adsorption kinetics study, only $\mathrm{HCl}-\mathrm{AC}$ was used as an adsorbent.

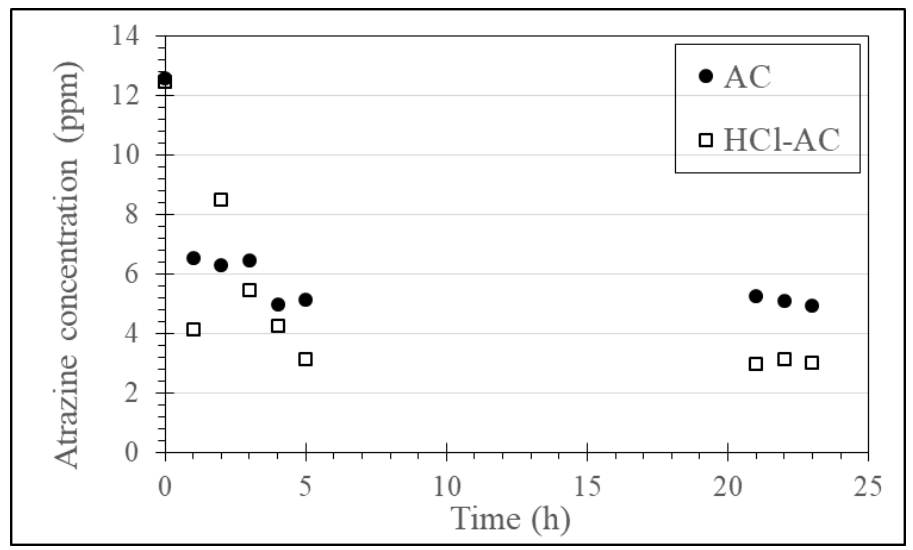

Fig. 1. The atrazine concentration in solution with time during adsorption by $\mathrm{AC}$ and $\mathrm{HCl}-\mathrm{AC}$.

For kinetics study, the atrazine solution with an initial concentration of $15 \mathrm{ppm}$ were prepared and adsorbed by $0.1 \mathrm{~g}$ of $\mathrm{HCl}-\mathrm{AC}$ with the agitation speed of $150 \mathrm{rpm}$. Four kinetics models were chosen to describe the adsorption that were Boyd, Weber and Morris, Pseudo-first order and Pseudo-second order models [18-20].

Boyd model is based on the assumption that the overall reaction is limited by intraparticle diffusion. It is generally applicable for the long duration process indicated by the amount of adsorbed adsorbate at any time divided by the adsorption capacity of adsorbent $\left(q_{t} / q_{e}\right)$ that is more than 0.85 . Moreover, the adsorbent is assumed to be sphere and the diffusion of adsorbate is homogeneous with a constant surface diffusivity $\left(\mathrm{D}_{\mathrm{s}}\right)$ at all points in particles. Boyd equation and its linearized form are shown in Eqs. (1) and (2), respectively.

$$
\begin{aligned}
& \frac{q_{t}}{q_{e}}=1-\left(\frac{6}{\pi^{2}}\right) \exp \left(\frac{-D_{s} \pi^{2} t}{r^{2}}\right) \\
& \ln \left(1-\frac{q_{t}}{q_{e}}\right)=\ln \left(\frac{6}{\pi^{2}}\right)-\left(\frac{-D_{s} \pi^{2} t}{r^{2}}\right)
\end{aligned}
$$

where $\quad q_{t} \quad$ - the amount of adsorbed adsorbate at any time $(\mathrm{mg} / \mathrm{g})$

$q_{e} \quad$ - the amount of adsorbed adsorbate at equilibrium or adsorption capacity $(\mathrm{mg} / \mathrm{g})$ 


$$
\begin{array}{ll}
r & \text { - radius of adsorbent particle }(\mathrm{cm}) \\
t & - \text { time (min) }
\end{array}
$$

Weber and Morris studied the adsorption. They also assumed that intraparticle diffusion is the limiting step of the overall process and their equation is expressed as shown in Eq. (3).

$$
q_{t}=k_{p} t^{1 / 2}+C
$$

where $\quad k_{p} \quad-$ rate constant for intraparticle diffusion ( $\mathrm{mg} / \mathrm{g} \mathrm{min}$ )

$C \quad-$ y-intercept of the linear graph. If this intercept is large, it implies that there is a great effect of boundary layer

Pseudo-first order and pseudo-second order kinetics models assume that the adsorption is the limiting step of overall reaction. The adsorption only occurs at the localized sites and there is no interaction between adsorbates. The maximum adsorption corresponds to a saturated monolayer of adsorbates adsorbent surface and the concentration of adsorbate is considered to be constant. For pseudo-first order model, in order to adsorb 1 molecule of adsorbate, 1 active site of adsorbent is required as the chemical equation shown in Eq. (4) and the adsorption rate is governed by first-order rate equation (Eq. (5)).

$$
\begin{aligned}
& A+S \leftrightarrow A S \\
& \frac{d q_{t}}{d t}=k_{1}\left(q_{e}-q_{t}\right)
\end{aligned}
$$

where $A$ - adsorbate molecule

$S \quad$ - active site of adsorbent

$k_{1} \quad$ - pseudo-first order equilibrium constant (1/min)

The linearised form of pseudo-first order equation is shown in Eq. (6).

$$
\log \left(q_{e}-q_{t}\right)=\log q_{e}-\frac{k_{1} t}{2.303}
$$

Pseudo-second order model is based on the similar assumptions with that of pseudo-first order model except it is required 2 active sites of adsorbent to adsorb 1 molecule of adsorbate and the adsorption is governed by second-order rate equation. The chemical equation assumed of this model is shown in Eq. (7) and the pseudo-second order equation and its linearised form are shown in Eqs. (8) and (9), respectively.

$$
\begin{aligned}
& A+2 S \leftrightarrow A S_{2} \\
& \frac{d q_{t}}{d t}=k_{2}\left(q_{e}-q_{t}\right)^{2} \\
& \frac{t}{q_{t}}=\frac{1}{k_{2} q_{e}^{2}}+\frac{t}{q_{e}}
\end{aligned}
$$

where $\quad k_{2} \quad-$ pseudo-second order equilibrium constant $(\mathrm{g} / \mathrm{kg} \mathrm{min})$

The experimental results were fitted with 4 mentioned kinetics models and the fitting graphs are shown in Fig. 2 and all kinetics parameters from these 4 models are shown in Table 2. It can be seen that the highest linear regression, $\mathrm{R}^{2}$, with the value of 0.9992 was 
obtained by fitting the data with pseudo-second order model. This implied that the adsorption of atrazine by $\mathrm{HCl}-\mathrm{AC}$ was limited by reaction step. In addition, this chemisorption required 2 active sites to adsorb 1 molecule of atrazine. According to the linearised plot in Figure $3 \mathrm{~d}$, the adsorption capacity of adsorbent $\left(q_{e}\right)$ and kinetics rate constant $\left(k_{2}\right)$ calculated from the slope and y-intercept of the graph were $32.8947 \mathrm{mg} / \mathrm{g}$ and $1.5005 \times 10^{-3} \mathrm{~g} / \mathrm{mg}$ min, respectively.

The results of this work were compared with other literatures as shown in Table 3. Comparing with multiwalled carbon nanotubes with various percentage of oxygen (MWCNTs) and PADs adsorbents, it can be seen that the surface area of $\mathrm{HCl}-\mathrm{AC}$ lies in broad cloud of the experimental values while its adsorption capacity was higher than that reported in the literatures $[21,22]$. This implied that HCl-AC had a better performance for atrazine removal comparing with MWCNTs and PADs even its surface area was lower. Meanwhile, our atrazine removal by $\mathrm{HCl}-\mathrm{AC}$ was compared by using other activated carbon derived by bio-wastes that were banana peels and palm oil shells. It was found that the atrazine removal efficiency and adsorption capacity of HCl-AC were higher than that of activated carbon derived from banana peels [23]. On the other hand, when compared the adsorption with activated carbon derived from palm shells [24], it can be observed that the adsorption performance of $\mathrm{HCl}-\mathrm{AC}$ was poorer than $\mathrm{PAC}, \mathrm{AC}-\mathrm{HNO}_{3}$ and $\mathrm{AC}-\mathrm{Ag}$ as a result of poorer adsorption capacity. Nevertheless, the results reported from the literatures were the best result attained by varying many parameters, e.g. $\mathrm{pH}$ and temperature, affecting the adsorption while that parameters were not varied in this work. Hence, the optimal condition for atrazine adsorption by $\mathrm{HCl}-\mathrm{AC}$ should be further studied.

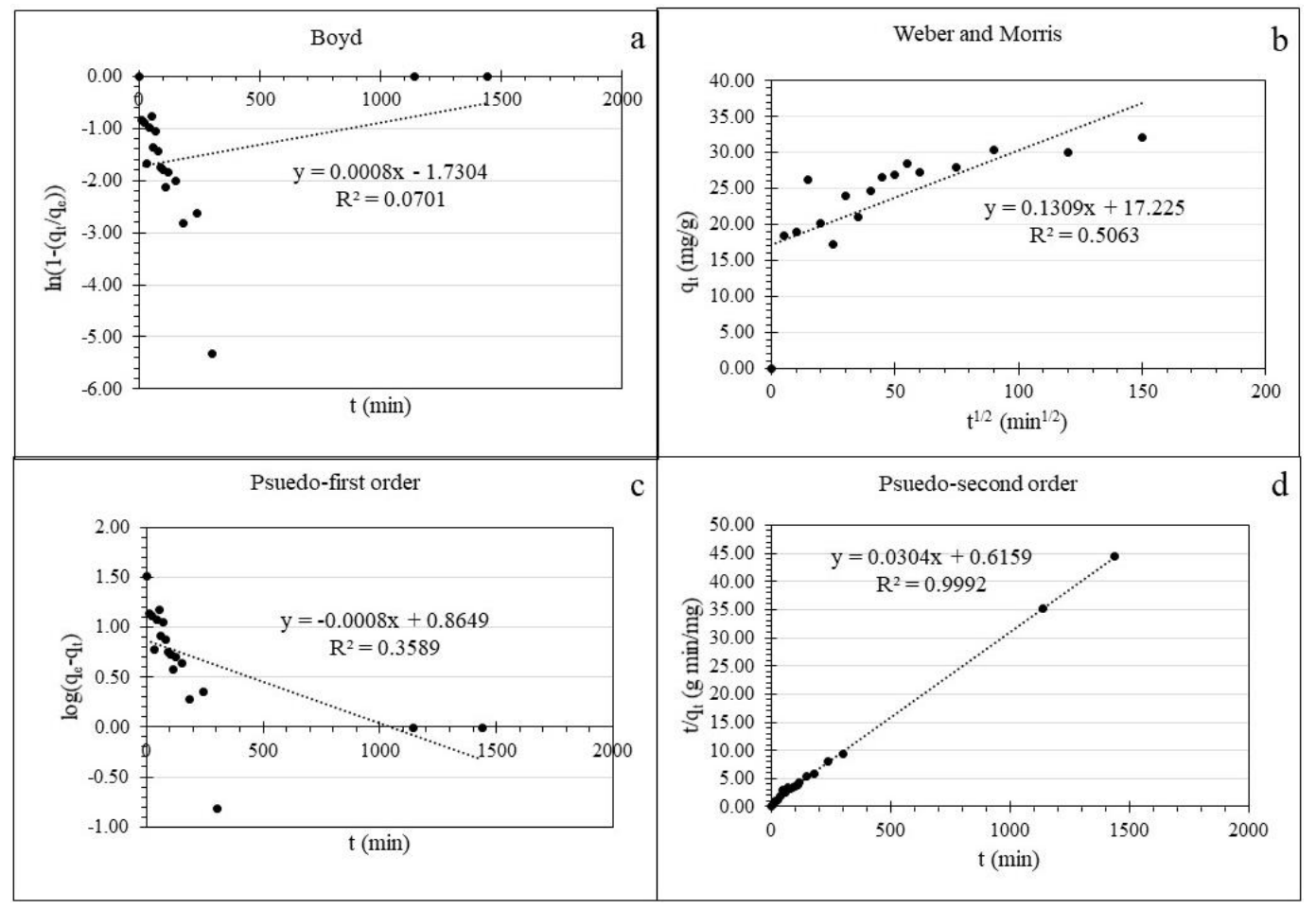

Fig. 2. Kinetics plots of atrazine adsorption by HCl-AC fitting with (a) Boyd, (b) Weber and Morris (c) pseudo-first order and (d) pseudo-second order models. 
Table 2. Kinetics parameters of Boyd, Weber and Morris, pseudo-first order and pseudo-second order models.

\begin{tabular}{|c|c|}
\hline Poyd & Value \\
$-\frac{D_{s} \pi^{2}}{r^{r}}(1 / \mathrm{min})$ & \\
$-R^{2}$ & 0.0008 \\
\hline Weber and Morris & 0.0701 \\
$-C(\mathrm{mg} / \mathrm{g})$ & 17.2250 \\
$-k_{p}\left(\mathrm{mg} / \mathrm{g} \min ^{1 / 2}\right)$ & 0.1309 \\
$-R^{2}$ & 0.5063 \\
\hline Pseudo-first order & 7.3266 \\
$-q_{e}(\mathrm{mg} / \mathrm{g})$ & $1.8424 \times 10^{-3}$ \\
$-k_{l}(1 / \mathrm{min})$ & 0.3589 \\
$-R^{2}$ & \\
\hline Pseudo-second order & 32.8947 \\
$-q_{e}(\mathrm{mg} / \mathrm{g})$ & $1.5005 \times 10^{-3}$ \\
$-k_{2}(\mathrm{~g} / \mathrm{mg}$ min $)$ & 0.9992 \\
$-R^{2}$ & \\
\hline
\end{tabular}

Table 3. Comparison of surface areas, atrazine removal efficiencies and pseudo-second order kinetics parameters of this work and literatures.

\begin{tabular}{|c|c|c|c|c|c|c|}
\hline Adsorbent & $\begin{array}{c}\text { Surface } \\
\mathbf{a r e a} \\
\left(\mathbf{m}^{2} / \mathbf{g}\right)\end{array}$ & $\begin{array}{c}\text { Removal } \\
\mathbf{e f f i c i e n c y ~} \\
\mathbf{( \% )}\end{array}$ & $\mathbf{q e}(\mathbf{m g} / \mathbf{g})$ & $\begin{array}{c}\mathbf{k}_{\mathbf{2}} \\
(\mathbf{g} / \mathbf{m g} \mathbf{m i n})\end{array}$ & $\mathbf{R}^{\mathbf{2}}$ & Ref. \\
\hline HCl-AC & 436 & 75.90 & 32.89 & $1.50 \times 10^{-3}$ & 0.9992 & This work \\
\hline $\begin{array}{c}\text { Multiwalled carbon } \\
\text { nanotubes-O (0.85\%) }\end{array}$ & 167 & N/A & 17.35 & $8.88 \times 10^{-4}$ & 1 & {$[21]$} \\
\hline $\begin{array}{c}\text { Multiwalled carbon } \\
\text { nanotubes-O (2.16\%) }\end{array}$ & 178 & N/A & 16.65 & $6.36 \times 10^{-4}$ & 1 & {$[21]$} \\
\hline $\begin{array}{c}\text { Multiwalled carbon } \\
\text { nanotubes-O (7.07\%) }\end{array}$ & 185 & N/A & 10.50 & $1.87 \times 10^{-3}$ & 1 & {$[21]$} \\
\hline $\begin{array}{c}\text { Nanoporous polymeric } \\
\text { adsorbent (PAD 400) }\end{array}$ & 720 & 96.00 & 3.77 & N/A & $>0.99$ & {$[22]$} \\
\hline $\begin{array}{c}\text { Nanoporous polymeric } \\
\text { adsorbent (PAD 610) }\end{array}$ & 490 & 96.00 & 1.68 & N/A & $>0.99$ & {$[22]$} \\
\hline $\begin{array}{c}\text { Activated carbon-derived } \\
\text { from banana peels }\end{array}$ & N/A & 51.40 & 14.90 & N/A & N/A & {$[23]$} \\
\hline $\begin{array}{c}\text { Palm oil shells activated } \\
\text { carbon (PAC) }\end{array}$ & N/A & N/A & 197.08 & $1.01 \times 10^{-5}$ & 0.9999 & {$[24]$} \\
\hline $\begin{array}{c}\text { Palm oil shells activated } \\
\text { carbon treated by HNO } 3 \\
\text { (AC-HNO3) }\end{array}$ & N/A & N/A & 191.00 & $2.41 \times 10^{-5}$ & 0.9986 & {$[24]$} \\
\hline $\begin{array}{c}\text { Palm oil shells activated } \\
\text { carbon treated by Ag (AC-Ag) }\end{array}$ & N/A & N/A & 193.03 & $6.91 \times 10^{-6}$ & 0.9973 & {$[24]$} \\
\hline
\end{tabular}




\section{Conclusions}

Activated carbon derived from water hyacinth was prepared in this work for atrazine adsorption from water. Three different chemical treatment methods; untreated (AC), $\mathrm{HCl}$-treated (HCl-AC) and $\mathrm{NaOH}$-treated $(\mathrm{NaOH}-\mathrm{AC})$, were accomplished in order to find the best method for activated carbon preparation. From BET and CHNS analysis showed that $\mathrm{HCl}-\mathrm{AC}$ was the best adsorbent with the highest surface area while $\mathrm{NaOH}-\mathrm{AC}$ could be the poorest adsorbent since it partly became ash during treatment. Form the adsorption experiments, it was found that the atrazine removal efficiencies of $\mathrm{AC}$ and $\mathrm{HCl}-\mathrm{AC}$ were $60.95 \%$ and $75.90 \%$, respectively. Moreover, 4 kinetics models were fitted with the experimental results. It can be observed that the results best fitted with pseudo-sencond order kinetics model with R2 of 0.9992 , the adsorption capacity of $32.89 \mathrm{mg} / \mathrm{g}$ and kinetics rate constant of $1.50 \times 10^{-3} \mathrm{~g} / \mathrm{mg} \mathrm{min}$.

\section{References}

1. Office of Agricultural Economics (2016) [Online]. Available: http://www.oae.go.th/ewt_news.php?nid=146, Accessed: 18-Nov-2017

2. A. Tawatsin, U. Thavara, P. Siriyasatien, Med. Res. Arch. 3, 1 (2015)

3. U.S. Department of Health and Human Services, ToxGuide for Atrazine (2003)

4. M. Graymore, F. Stagnitti, G. Allinson, Environ. Int. 26, 483 (2001)

5. T. B. Hayes, V. Khoury, A. Narayan, M. Nazir, A. Park, T. Brown, L. Adame, E. Chan, D. Buchholz, T. Stueve, S. Gallipeau, Proc. Natl. Acad. Sci. 107, 4612 (2010)

6. D. J. Brusick, Mutat. Res. Genet. Toxic. 317, 133 (1994)

7. M. Pucarevic, N. Stojic, I. Kuzmanovski, Kuwait J. Sci. 44, 99 (2017)

8. J. M. Salman, V. O. Njoku, B. H. Hameed, Chem. Eng. J. 174, 41 (2011)

9. T. A. H. Nguyen, H. H. Ngo, W. S. Guo, J. Zhang, S. Liang, Q. Y. Yue, Q. Li, T. Nguyen, Bioresour. Technol. 148, 574 (2013)

10. N. Chaukura, W. Gwenzi, N. Tavengwa, M. M. Manyuchi, Environ. Dev. 19, 84 (2016)

11. H. P. Chao, C. C. Chang, A. Nieva, J. Ind. Eng. Chem. 20, 3408 (2014)

12. S. De Gisi, G. Lofrano, M. Grassi, M. Notarnicola, Sustain. Mater. Technol. 9, 10 (2016)

13. H. A. Hegazi, HBRC J. 9, 276 (2013)

14. Y. Zhou, L. Zhang, Z. Cheng, J. Mol. Liq. 212, 739 (2015)

15. M. Cock (2001) [Online]. Available: https://www.cabi.org/isc/FullTextPDF/2009/20093238351.pdf, Accessed: 30-May2018

16. M. Badiei, N. Asim, J. M. Jahim, K. Sopian, APCBEE Procedia 9, 170 (2014)

17. S. S. Chen, J. S. Taylor, L. A. Mulford, C. D. Norris, Desalination 160, 103 (2004)

18. B. Seyhi, P. Drogui, P. Gortares-Moroyoqui, M. I. Estrada-Alvarado, L. H. Alvarez, J. Chem. Technol. Biotechnol. 89, 1811 (2014)

19. T. O. Isichei, F. E. Okieimen, Environ. Pollut. 3, 99 (2014)

20. A. M. El-Wakil, W. M. El-Maaty, F. S. Awad, J. Anal. Bioanal. Tech. 5, 1 (2014) 
21. G. C. Chen, X. Q. Shan, Y. Q. Zhou, X. E. Shen, H. L. Huang, S. U. Khan, J. Hazard. Mater. 169, 912 (2009)

22. I. Y. Ipek, Sep. Sci. Technol. 49, 2358 (2014)

23. A. Chaparadza, J. M. Hossenlopp, Water Sci. Technol. 65, 940 (2012)

24. N. Y. Rachel, K. Daouda, B. Abdelaziz, D. Djimi, E. Gaelle, Y. Abdelrani, K. Mbadcam, IJSRT 5, 128 (2016) 